\title{
Schizophrenia trials conducted in African countries: a drop of evidence in the ocean of morbidity?
}

Marianna Purgato ${ }^{1,2^{*}}$, Clive Adams ${ }^{1}$ and Corrado Barbui ${ }^{2}$

\begin{abstract}
Objective: To quantify schizophrenia trialling activity in African countries and to describe the main features of these trials.

Methods: We searched the Cochrane Schizophrenia Group Register, which contains 16,000 citations to 13,000 studies relating only to people with schizophrenia or schizophrenia-like illness, to identify schizophrenia trials conducted in Africa without time limitation.

Results: A total of 38 trials met the inclusion criteria and were included in our analysis. Of the 54 countries of Africa, only 8 produced at least one trial: South Africa produced the majority of trials ( 20 out of 38 trials, $53 \%$ ), followed by Nigeria (7 out of 38 trials, 18\%) and Egypt (4 out of 38 trials, 11\%). The majority of studies investigated the efficacy of pharmacological interventions, were short in duration, and employed a double-blind design. The quality of reporting was generally poor. We found six trials comparing antipsychotics from the WHO Essential List of Medicine versus new generation antipsychotics. In terms of efficacy and acceptability, these studies failed to show any advantage of newer antipsychotics over first-generation agents.

Conclusions: We observed an impressive mismatch between the number of individuals with schizophrenia living in African countries, estimated to be around 10 million, and the overall number of patients included in African trials, which is less than 2,000. These few trials were of low quality and appeared not to reflect the real needs of the population. We argue that the concept of pragmatism should be introduced into the design of randomized trials in African countries. Pragmatic trials should investigate whether treatments, given in real-world circumstances, really have clinically meaningful effects.
\end{abstract}

Keywords: Clinical trials, Africa, Schizophrenia

\section{Introduction}

Most of the global burden of mental illness falls to the poorest nations, where $80 \%$ of world's population live [1]. Africa is the second-most-populated continent, with around 1 billion people, or $15 \%$ of the world's population. For schizophrenia, a major psychiatric disorder that affects about $0.5 \%$ of world population [2], it has been estimated that between 4 and 5 million individuals afflicted by these severe psychiatric disorders live in African countries [2]. Despite these impressive numbers,

\footnotetext{
* Correspondence: marianna.purgato@univr.it

${ }^{1}$ Division of Psychiatry, University of Nottingham, Nottingham, UK

${ }^{2}$ Department of Public Health and Community Medicine, Section of Psychiatry, University of Verona, Verona, Italy
}

the worldwide deficit of research about psychiatric disorders is particularly acute in low- and middle-income countries (LAMICs), including several African countries [3]. LAMICs devote less than $1 \%$ of their health expenditure to mental health and have poorly developed mental health policies and research infrastructures [4].

For patients, carers and policymakers local data are important. Even well-conducted trials, if undertaken in a very dissimilar care-culture may be difficult to apply. Local trials are important and informative whether they agree or disagree other similar studies from afar. All evidence must be considered but the local perspective not ignored. The quality of any trialling activity is another crucial issue, as it may vary across nations $[5,6]$. For

\section{Biomed Central}


example, the volume and quality of trial research from China has been considered in many surveys and quality remains a major concern [7-11]. Elsewhere it has been shown that pioneering mental health trials from LAMICs are of as mixed quality as their more accessible counterparts from richer nations, but cannot be identified in commonly used bibliographic databases [12].

The Cochrane Schizophrenia Group produces and maintains a register of all studies [13]. This involves regular and systematic searching of 71 databases worldwide. The studies identified in this way are reliably indexed by country.

The aim of this work is to quantify schizophrenia trialling activity in African countries and to provide detailed information on the main clinical and methodological features of these trials. Our analysis could be used by researchers and policy makers to help plan future research to cover the mental health needs of African population.

\section{Methods}

\section{Search methods for identification of studies}

We searched the Cochrane Schizophrenia Group Register to identify any trial conducted in Africa without time limitation. The Cochrane Schizophrenia Group Register contains 16,000 citations to 13,000 studies relating only to people with schizophrenia or schizophrenia-like illness [13]. The register includes all published and unpublished references to randomized, quasi randomized and controlled clinical trials without language restrictions. These studies are indexed regarding the country of origin, the interventions under study and the number of participants. The last version of register was February 2012.

\section{Types of studies}

We included all randomised controlled trials and controlled clinical trials undertaken in any African country. Included studies compared any pharmacological and non-pharmacological treatments with other active treatments or placebo. Only studies that enrolled patients in Africa were considered. Multicentre studies were included only if all centres enrolling patients were located in Africa.

\section{Types of participants}

Participants were in- and out-patients of both sexes, with a primary diagnosis of schizophrenia and related psychotic disorders, according to the criteria described in the DSM, ICD, or according to any other clinical or standardized criteria.

\section{Selection of trials}

Included and excluded studies were collected following the Preferred Reporting Items for Systematic reviews and Meta-Analyses - PRISMA flow diagram [14]. From the Cochrane Schizophrenia Group Register we extracted all records corresponding to studies carried out in Africa. We examined all titles and abstracts, and obtained full texts if the word "random" or "randomised" or "control" or "controlled" was present in the title and/or abstract. $\mathrm{MP}$ and $\mathrm{CB}$ read the full texts, determined whether they met inclusion criteria and extracted the data. Considerable care was taken to exclude duplicate publications.

\section{Assessment of risk of bias in included studies}

For quality assessment we used the Cochrane risk-ofbias tool (Oxford, England, Cochrane Collaboration). This instrument consists of seven items [15]. Two of the items assess the strength of the randomization process in preventing selection bias in the assignment of participants to interventions: adequacy of sequence generation and allocation concealment. The third and fourth items assess the influence of performance bias and detection bias on the study results. The fifth item assesses the likelihood of incomplete outcome data, which raise the possibility of bias in effect estimates. The sixth item assesses selective reporting, the tendency to preferentially report statistically significant outcomes. This item requires a comparison of published data with trial protocols, when such are available. The final item refers to other sources of bias that are relevant in certain circumstances, such as, for example, sponsorship bias.

\section{Data extraction}

The following information was extracted using an electronic spreadsheet: year of publication, geographic area (country of Africa), type of experimental and control intervention, sample size, weeks of follow-up, diagnostic criteria, number of outcome measures, Gross Domestic Product (GDP) at the time when each study was carried out. For studies that compared antipsychotics included in the WHO Essential List of Medicines [16] with new generation antipsychotics we additionally extracted efficacy and acceptability data. For efficacy data, the mean change from baseline to endpoint, or the mean scores at endpoint, at the Brief Psychiatric Rating Scale (BPRS) or Positive and Negative Syndrome Scale (PANSS) were extracted, together with the standard deviation (SD) or standard error (SE) of these values, and the number of patients included in these analyses. For acceptability data, the number of patients leaving the study early for any reason was extracted.

\section{Data presentation}

We calculated simple percentages (\%). To ascertain whether sample size and number of efficacy measures have increased in the last 40 years, we used a box plot diagram and a nonparametric test for trend (extension 
of the Wilcoxon rank-sum test). For each study that compared antipsychotics included in the WHO Essential List of Medicines with new generation antipsychotics, efficacy and acceptability data were entered and analyzed using the Cochrane Collaboration's Review Manager software version 5.1 (Oxford, England, Cochrane Collaboration). Continuous data were analyzed using standardized mean differences (SMDs) with the random-effects-model (with 95\% confidence intervals [CI]); for dichotomous outcomes, the odds ratio (OR) was calculated based on the random effects model (with 95\% CI). This approach was used to present the results of individual studies, but no overall treatment estimates were calculated.

\section{Results}

\section{Characteristics of included studies}

The original search yielded 69 records, of which 27 were excluded because ineligible or not relevant. The remaining 42 records were assessed for eligibility. Thirty-eight trials met the inclusion criteria and were included in our analysis (Figure 1) (for references of included studies, see reference list from [17-54]).

Eight out of the 54 countries of Africa produced at least one trial (Figure 2). South Africa produced the majority of trials (20 out of 38 trials, $53 \%$ ), followed by Nigeria ( 7 out of 38 trials, 18\%) and Egypt (4 out of 38 trials, 11\%). These countries had the highest Gross Domestic Product compared with the other countries producing trials in Africa (Figure 2). The characteristics of all included studies are presented in Table 1 . The majority of studies investigated pharmacological interventions, with a drug versus drug design in most cases (33 out of 38 trials, $87 \%$ ). Most studies were short in duration (22 out of 38 had a follow-up $\leq 12$ weeks, $58 \%$ ), had a double-blind design and used standardized diagnostic criteria (DSM or ICD). Local ethics committee approval has been mentioned in 22 out of 38 studies. Fifteen studies were funded by pharmaceutical industries, three

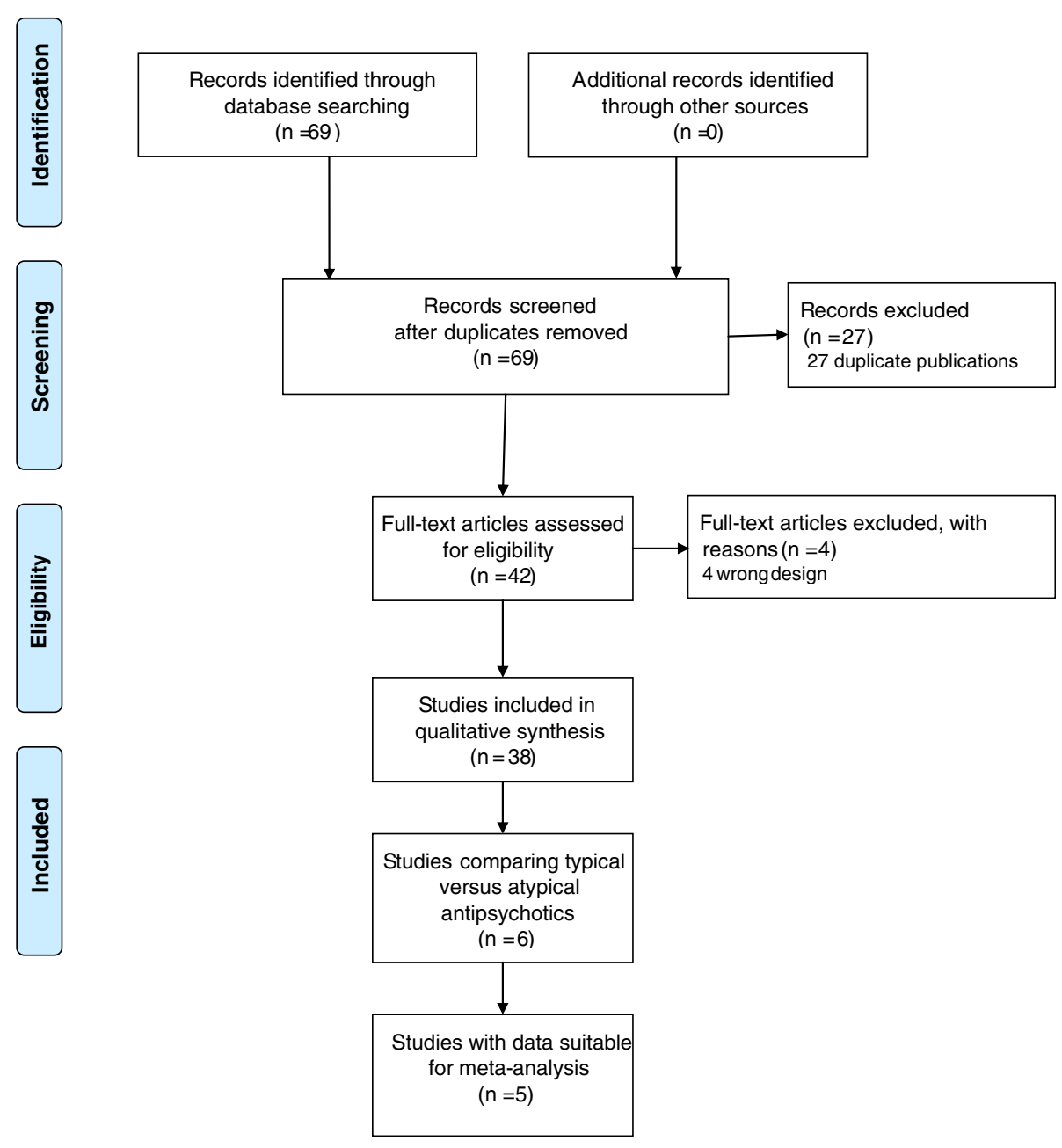

Figure 1 PRISMA Flow diagram. 


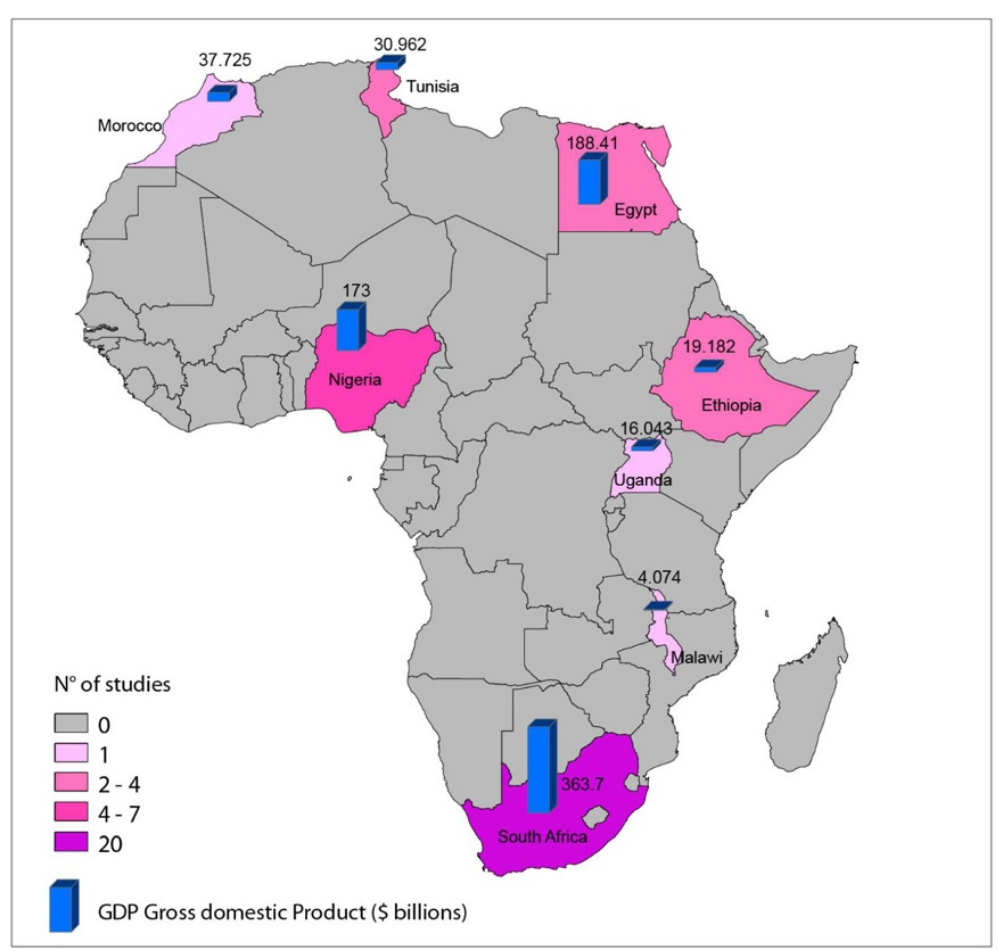

Figure 2 Distribution of schizophrenia trials by African country and Gross Domestic Product.

studies were independent from drug industry and in remaining 20 studies the role of sponsorship was unclear (Table 1).

While sample size only minimally increased over time (Figure 3), as shown by Spearman's rank correlation coefficient (rho $=0.333 ; p=0.043$ ), the number of outcomes measures significantly increased over time ( $r h o=0.357$; $p<0.027)$.

\section{Risk of bias}

The standard of reporting was generally poor (Figure 4) (For study by study risk of bias, see Additional file 1). The generation of the randomization sequence and the concealment of allocation were not properly described in the majority of studies. Blinding was adopted in some studies, but not accurately described. The risk of other bias, such as sponsorship bias, could not be excluded, as several studies received financial support from pharmaceutical industries.

\section{Essential antipsychotics versus new generation antipsychotics}

Six trials compared antipsychotics from the WHO essential list of medicine versus new generation antipsychotics. Essential antipsychotics were haloperidol and chlorpromazine; new generation antipsychotics were quetiapine, olanzapine and risperidone. Efficacy and acceptability data, available for 5 studies only, are presented in Figures 5 and 6 , respectively. In terms of efficacy, three studies comparing haloperidol versus new generation antipsychotics failed to show any difference. Studies comparing chlorpromazine versus olanzapine provided contrasting evidence. In one study chlorpromazine was less effective than olanzapine $(\mathrm{SMD}=1.55$, 95\% CI 0.78 to $2.32 \mathrm{n}=39$ ), in the other one chlorpromazine was slightly more effective than olanzapine (SMD $-0.58,95 \% \mathrm{CI}-1.24$ to $0.08 \mathrm{n}=41$ ) (Figure 5). In terms of acceptability, studies failed to show any difference (Figure 5).

\section{Discussion}

To our knowledge, this is the first survey investigating content and quality of schizophrenia trials carried out in African countries. A first impressive result is the mismatch between the number of individuals with schizophrenia living in African countries, estimated to be around 5 million [2], and the overall number of patients included in African trials, which is less than 2,000 (accounting for $0.001 \%$ of patients included in the totality of trials conducted in schizophrenia at a global level according to the Cochrane Schizophrenia Register) (http://szg.cochrane.org/cochrane-schizophrenia-group- 


\section{Table 1 Characteristics of schizophrenia trials conducted in Africa}

\begin{tabular}{|c|c|}
\hline & STUDIES $(n=38)$ No $\%$ \\
\hline \multicolumn{2}{|l|}{ Type of comparison } \\
\hline Typical AP versus typical AP & $12(31.58)$ \\
\hline Typical AP versus placebo & $3(7.89)$ \\
\hline Typical AP versus no treatment & $1(2.63)$ \\
\hline Typical AP versus atypical AP & $6(15.79)$ \\
\hline Atypical AP versus atypical AP & $4(10.53)$ \\
\hline Other pharmacological interventions & $7(18.42)$ \\
\hline Non pharmacological interventions & $5(13.16)$ \\
\hline \multicolumn{2}{|l|}{ Year of publication } \\
\hline 1970-1985 & $9(23.68)$ \\
\hline 1986-2000 & $9(23.68)$ \\
\hline $2001-2010$ & $20(52.64)$ \\
\hline \multicolumn{2}{|l|}{ Sample size } \\
\hline Min-20 & $4(10.81)$ \\
\hline $21-40$ & $12(32.43)$ \\
\hline $41-60$ & $10(27.03)$ \\
\hline 61-Max & $11(29.73)$ \\
\hline \multicolumn{2}{|l|}{ Arms } \\
\hline Two arms & $34(89.47)$ \\
\hline Three arms or more & $4(10.53)$ \\
\hline \multicolumn{2}{|l|}{ Weeks of follow-up } \\
\hline$<6$ weeks & $16(42.43)$ \\
\hline 6-12 weeks & $9(24.24)$ \\
\hline 13-24 weeks & $7(18.18)$ \\
\hline$>24$ weeks & $6(15.15)$ \\
\hline \multicolumn{2}{|l|}{ Blinding } \\
\hline Open label & $6(15.79)$ \\
\hline Single blind & $7(18.42)$ \\
\hline Double blind & $18(47.37)$ \\
\hline Unclear & $7(18.42)$ \\
\hline \multicolumn{2}{|l|}{ Diagnostic criteria } \\
\hline Unclear & $9(23.68)$ \\
\hline DSM+ - ICD+† & $25(65.79)$ \\
\hline Clinical diagnosis & $4(10.53)$ \\
\hline \multicolumn{2}{|l|}{ Number of outcomes } \\
\hline Min-5 & $13(34.21)$ \\
\hline $6-10$ & $14(36.84)$ \\
\hline 11-Max & $11(28.95)$ \\
\hline \multicolumn{2}{|l|}{ Ethics committee approval } \\
\hline Unclear & $16(42.11)$ \\
\hline Yes & $22(57.89)$ \\
\hline \multicolumn{2}{|l|}{ Sponsor (drug company) } \\
\hline Unclear & $20(52.63)$ \\
\hline
\end{tabular}

Table 1 Characteristics of schizophrenia trials conducted in Africa (Continued)

\begin{tabular}{lc}
\hline Yes & $15(39.48)$ \\
Independent study & $3(7.89)$ \\
\hline
\end{tabular}

specialised-register). The mismatch is even more striking if one considers that $15 \%$ of the world population lives in Africa, but only $0.005 \%$ of the world schizophrenia trials have been conducted in the continent (Figure 7). As one might expect, the great majority of trials on schizophrenia are conducted in high-income countries (32\% in North America and 26\% in Europe), but emergent countries like China, Brazil or India -with a middle-low or low Gross Domestic Product- are having a recent burgeoning of work [6]. For example, even if Chinese trials are often described as poor in methodological quality $[9,55]$, China produced in the last decade a great amount of randomized trials $(22 \%$ of all schizophrenia trials coded in the Cochrane Schizophrenia Group Register come from China) [6]. Also from Brazil and India there are examples of emergent high quality research activity [56].

A second issue is that these few trials appear not to reflect the real needs of the population. The World Mental Health surveys showed that more than $75 \%$ of those identified with serious mental disorders in LAMICs received no care at all, despite substantial role disability [57]. In sub-Saharan Africa, the treatment gap for schizophrenia and other psychoses has been shown to exceed $90 \%$. Additionally, even where treatment is provided, it often is far below minimum acceptable standards. In such a situation it seems difficult to believe that trials addressing the efficacy of antipsychotic drugs versus placebo, or trials aiming to ascertain the added value of new generation antipsychotics over inexpensive "essential" antipsychotics can be seen as a priority. If one additionally considers that most trials were underpowered, failed to report basic methodological details such as, for example, information about the methods of random allocation, and its concealment from the study investigators, or how blinding was preserved, than the overall situation seems even more desolating, as the practical contribution of these studies to African patients, carers and policymakers is at least questionable. Unfortunately, trial quality has not substantially increased over time: while sample size increased only minimally over time, patient selection criteria and outcome assessments have become much more sophisticated, as suggested by the increase in use of standardized diagnostic criteria and by the steadily increase in the number of outcome measures. Although this trend may have increased the internal validity of findings, it has nevertheless allowed study of 


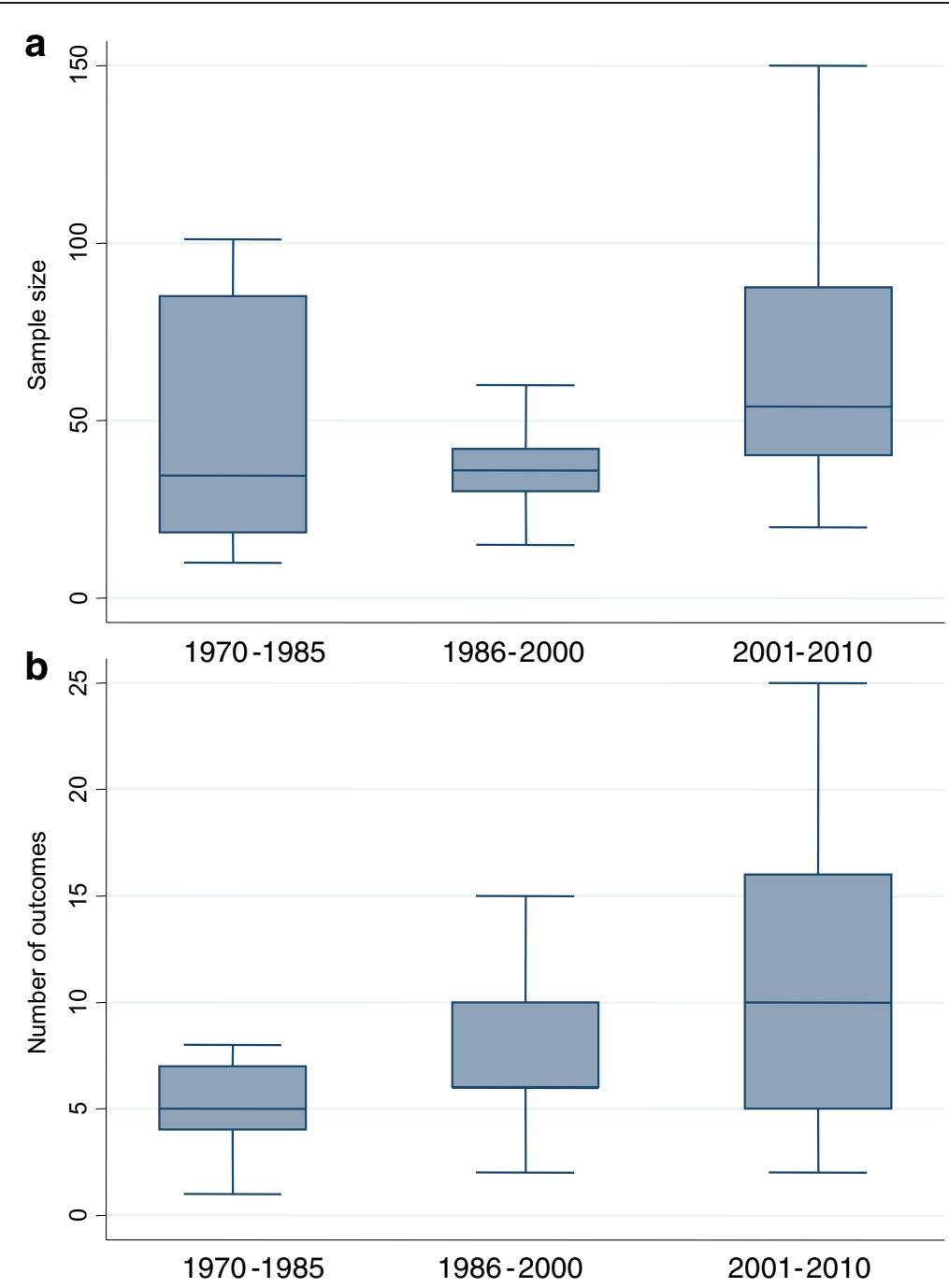

Figure 3 Distribution of schizophrenia trials carried out in Africa by sample size (a) and number of outcome measures (b) from 1970 to $\mathbf{2 0 1 0}$. The horizontal line represents the median, the box extends to cover the interquartile range and the vertical line extends to the extremes.

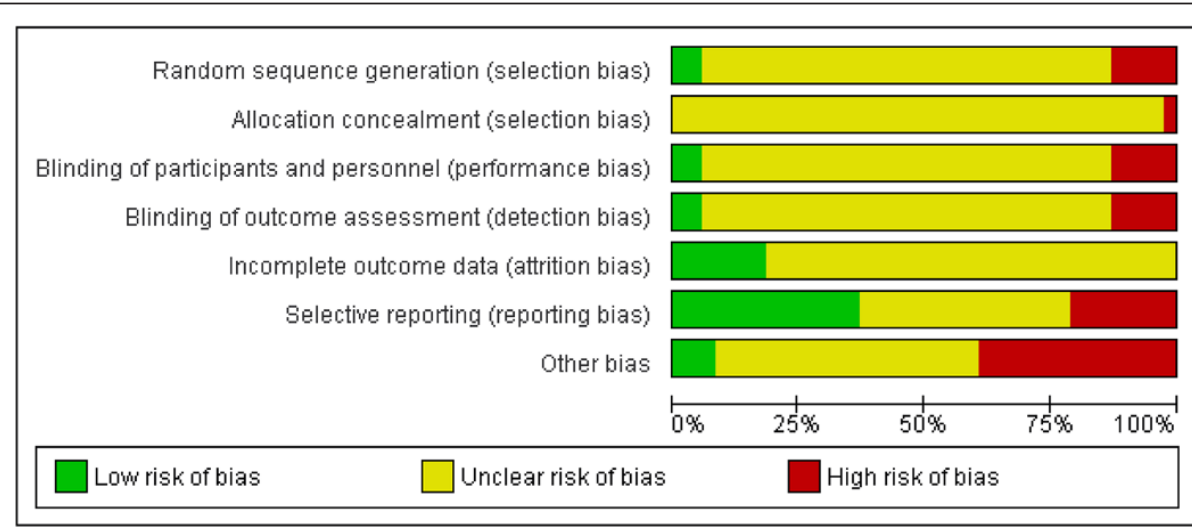

Figure 4 Methodological quality graph: review authors' judgements about each methodological quality item presented as percentages across all included studies. 


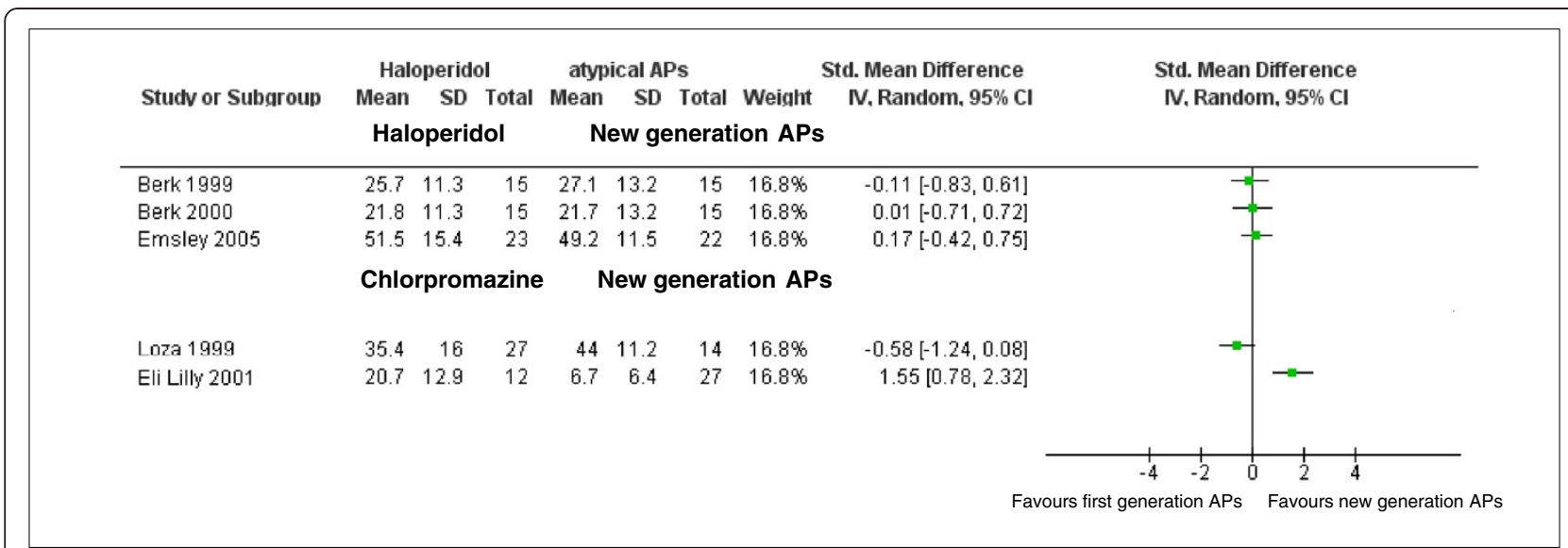

Figure 5 Efficacy data of schizophrenia trials conducted in Africa comparing antipsychotics included in the WHO List of Essential Medicines (haloperidol and chlorpromazine) with new generation antipsychotics.

only highly refined groups of people with schizophrenia. This increasing drift from real world practice makes it difficult to apply trial results to typical patients [58]. Similarly, we observed that the number of outcome measures has increased during the last 40 years. This confusion of measuring suggests, at the very least, a lack of consensus on what is important.

Instead of increasing the drift from real world practice, randomized trials should be able to enroll real-world patients populations to be followed under real-world circumstances and assessed with outcome measures that are used in practice. As has already been happening in many other countries of the world, the concept of pragmatism should be introduced into the design of randomized trials in African countries. Pragmatic trials should investigate whether treatments, given in real-world circumstances, really have clinically meaningful effects. An example of this attitude is the series of TREC studies carried out in Brazil and India which randomized treatments given in day to day practice, left all subsequent decisions to clinicians, and used routine data as primary outcomes [59-62]. The concept of pragmatism could be similarly applied to the purpose of clinical trials, with a strong focus and commitment to answering questions of high public health relevance. Examples of trials undertaken with this logic are available, for example in the area of interventions for psychosocial wellbeing in humanitarian settings [63]. Another pragmatic area of interest is implementation science [64], with a focus on investigating the most effective interaction between specialist and non-specialist care providers, such as the extent to which tasks can be shifted and the duration, type, and frequency of training and supervision that are required. WHO has recently produced an evidence-based intervention package with recommendations to facilitate care at first and second

\begin{tabular}{|c|c|c|c|c|c|c|c|c|}
\hline Study or Subgroup & \multicolumn{2}{|c|}{ Haloperidol } & \multicolumn{4}{|c|}{ Newgeneration APs } & \multicolumn{2}{|c|}{$\begin{array}{c}\text { Odds Ratio } \\
\text { M-H, Random, } 95 \% \mathrm{Cl}\end{array}$} \\
\hline Berk 1999 & 1 & 15 & 2 & 15 & $12.6 \%$ & $0.46[0.04,5.75]$ & & \\
\hline Berk 2000 & 1 & 15 & 1 & 15 & $9.7 \%$ & $1.00[0.06,17.62]$ & & \\
\hline \multirow[t]{2}{*}{ Emsley 2005} & 8 & 23 & 10 & 22 & $55.3 \%$ & $0.64[0.19,2.13]$ & & \\
\hline & \multicolumn{2}{|c|}{ Chlorpromazine } & \multicolumn{3}{|c|}{ New generation APs } & & & \\
\hline Loza 1999 & 3 & 27 & 1 & 14 & $14.3 \%$ & $1.63[0.15,17.24]$ & & \\
\hline \multirow[t]{3}{*}{ Eli Lilly 2001} & 2 & 12 & 0 & 27 & $8.2 \%$ & $13.10[0.58,296.12]$ & & \\
\hline & & & & & & & $\begin{array}{ll} \\
0.02 & 0.1\end{array}$ & 50 \\
\hline & & & & & & & Favours first generation APs & Favours new generation APs \\
\hline
\end{tabular}

Figure 6 Acceptability data (total dropout rates) of schizophrenia trials conducted in Africa comparing antipsychotics included in the WHO List of Essential Medicines (haloperidol and chlorpromazine) with new generation antipsychotics. 


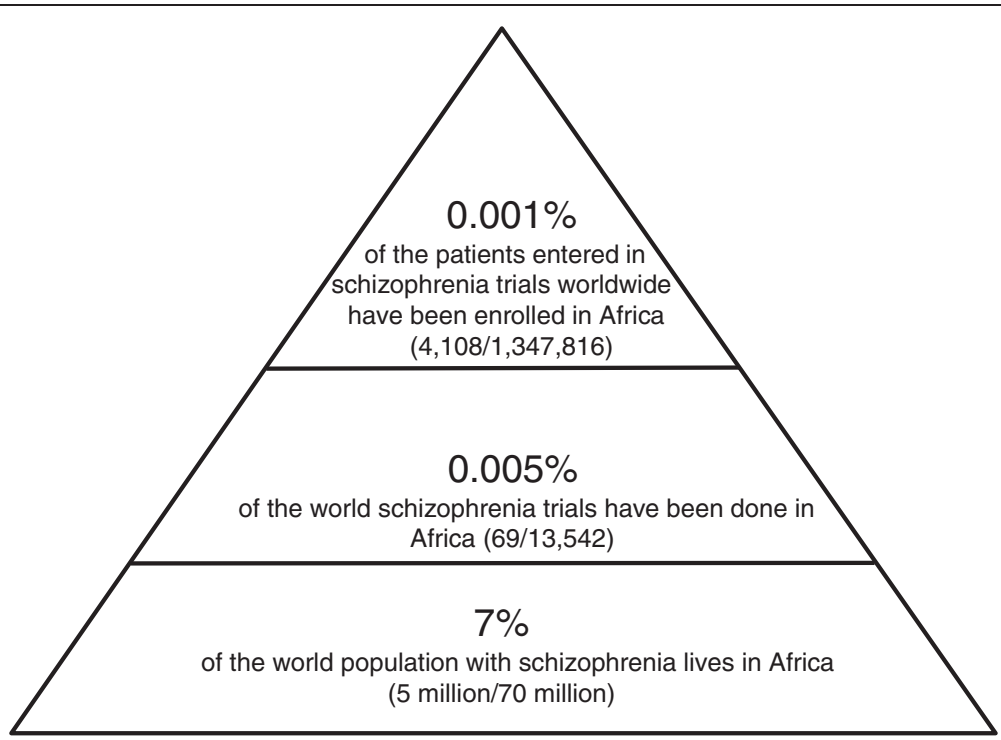

Figure 7 Pyramid describing the mismatch between the number of individuals with schizophrenia living in African countries and the number of trials conducted, and patients involved, in African countries.

level facilities by the non-specialist health care providers in low and middle income countries $[65,66]$, but no randomized evidence exists on how this package should be implemented to maximize benefit at sustainable costs. Researchers and funders have tremendous responsibility in this context. Consortia and networks, advocacy organizations, universities and their partners should organize their activities considering that the implementation of a new generation of randomized trials in African countries is a pressing priority [64].

The present analysis has limitations. First, we did not include international multicentre studies where African countries were single sites, possibly loosing studies with good sample sizes and potentially better reporting. Second, despite the extensive searches, the possibility that some relevant studies have not been identified cannot be ruled out. The Cochrane Schizophrenia Group maintains a trial register by regularly and systematically searching 71 databases worldwide. However, it is possible that some journals are not indexed in these databases, and there might be some other local databases that are not included in our searches. Other factors are that some databases have become available only recently, and poor indexing within some databases may have impaired retrieval. We argue that accessibility to trials conducted in African countries should be improved by prospective registration of all future trials, as endorsed by the International Committee of Medical Journal Editors (ICMJE) [67] and the World Health Organization's International Clinical Trials Registry Platform [68].

In conclusion, this study generates information on the clinical and methodological characteristics of trials conducted in Africa on schizophrenia interventions. This information is needed to plan and implement future schizophrenia clinical trials, to suggest research areas that may have not received adequate attention, and to point to methodological aspects that need to be addressed when planning future trialling activities.

\section{Additional file}

Additional file 1: Risk of bias of included studies.

\section{Competing interests}

The authors declare that they have no competing interest.

\section{Authors' contributions}

MP, CEA and CB designed the study. MP extracted data, MP and CB analyzed and interpreted data. MP and CB drafted the first manuscript. CEA commented and refined the manuscript in preparation for submission. All authors approved the final version to be published.

\section{Acknowledgements}

Authors would like to thank Samantha Roberts for providing updated searches from the Cochrane Schizophrenia Group Register.

Received: 15 May 2012 Accepted: 7 June 2012

Published: 6 July 2012

\section{References}

1. Scaling up care for mental, neurological, and substance use disorders; http://www.who.int/mental_health/mhgap_final_english.pdf.

2. Saha S, Chant D, Welham J, McGrath J: A systematic review of the prevalence of schizophrenia. Plos Med 2005, 2:e141.

3. Large M, Nielssen O, Farooq S, Glozier N: Increasing rates of psychiatric publication from low- and middle-income countries. Int J Soc Psychiatry 2010, 56:497-506.

4. Sheriff RJ, Adams CE, Tharyan P, Jayaram M, Duley L: Randomised trials relevant to mental health conducted in low and middle-income countries: a survey. BMC Psychiatry 2008, 8:69. 
5. Thornley B, Adams C: Content and quality of 2000 controlled trials in schizophrenia over 50 years. BMJ 1998, 317:1181-1184.

6. Miyar J, Adams CE: Content and Quality of 10000 Controlled Trials in Schizophrenia Over 60 Years. Schizophr Bull 2012, Jan 30. [Epub ahead of print].

7. Chakrabarti A, Adams CE, Rathbone J, Wright J, Xia J, Wong W, Von RP, Koenig C, Baier S, Pfeiffer C, et al: Schizophrenia trials in China: a survey. Acta Psychiatr Scand 2007, 116:6-9.

8. Xia J, Wright J, Adams CE: Five large Chinese biomedical bibliographic databases: accessibility and coverage. Health Info Libr J 2008, 25:55-61.

9. Zhang D, Yin P, Freemantle N, Jordan R, Zhong N, Cheng KK: An assessment of the quality of randomised controlled trials conducted in China. Trials 2008, 9:22

10. Chen Y, Li J, Ai C, Duan Y, Wang L, Zhang M, Hopewell S: Assessment of the quality of reporting in abstracts of randomized controlled trials published in five leading Chinese medical journals. PLoS One 2010, 5:e11926.

11. Koesters M, Zhang Y, Chun Y, Weinmann S, Becker T, Jin WD: What can we learn from chinese randomized controlled trials? A systematic review and meta-analysis of chinese venlafaxine studies. J Clin Psychopharmacol 2011, 31:194-200.

12. Adams CE, Tharyan P, Coutinho ES, Stroup TS: The schizophrenia drugtreatment paradox: pharmacological treatment based on best possible evidence may be hardest to practise in high-income countries. BrJ Psychiatry 2006, 189:391-392.

13. Cochrane Schizophrenia Group Specialised Register; http://szg.cochrane.org/ cochrane-schizophrenia-group-specialised-register.

14. Moher D, Liberati A, Tetzlaff J, Altman DG: Preferred reporting items for systematic reviews and meta-analyses: the PRISMA statement. BMJ 2009, 339:b2535.

15. Cochrane Handbook for systematic reviews of interventions. Version 5.1.0. The Cochrane Collaboration.

16. WHO Model Lists of Essential Medicines; http://www.who.int/medicines/ publications/essentialmedicines/en/

17. Agara AJ, Onibi OE: Effects of group psychoeducation (GPE) on compliance with scheduled clinic appointments in a neuro-psychiatric hospital in southwest Nigeria: a randomised control trial (RCT). Ann Acad Med Singapore 2007, 36:272-275.

18. Anumonye A, Onibuwe-Johnson T, Marinho AA: Clinical trial of pimozide. West Afr J Pharmacol Drug Res 1976, 3:17-24.

19. Askar AM, Rakhawy YT, El-Guindy T: Thioridazine in treatment of psychiatric patients. J Egypt Med Assoc 1963, 46:918-932.

20. Berk M, Brook S, Trandafir Al: A comparison of olanzapine with haloperidol in cannabis-induced psychotic disorder: a double-blind randomized controlled trial. Int Clin Psychopharmacol 1999, 14:177-180

21. Berk M, Ichim C, Brook S: Efficacy of mirtazapine add on therapy to haloperidol in the treatment of the negative symptoms of schizophrenia: a double-blind randomized placebo-controlled study. Int Clin Psychopharmacol 2001, 16:87-92.

22. Berk M, Brook S, Nur F: Risperidone compared to haloperidol in cannabis-induced psychotic disorder: A double blind randomized controlled trial. Int J Psychiatry in Clin Pract 2000, 4:139-142.

23. Botha UA, Koen L, Joska JA, Hering LM, Oosthuizen PP: Assessing the efficacy of a modified assertive community-based treatment programme in a developing country. BMC Psychiatry 2010, 10:73.

24. Brook S, Berk M, Selemani S, Kolloori J, Nzo I: A randomized controlled double blind study of zuclopenthixol acetate compared to haloperidol in acute psychosis. Hum Psychopharmacol 1998, 13:17-20.

25. Desta M, Tadesse A, Gebre N, Barci BM, Torrey EF, Knable MB: Controlled trial of hydroxychloroquine in schizophrenia. J Clin Psychopharmacol 2002, 22:507-510.

26. El-Islam MF, Ahmed SA, Erfan ME: The effect of unilateral E.C.T. on schizophrenic delusions and hallucinations. Br J Psychiatry 1970, 117:447-448.

27. Emsley R, Turner HJ, Schronen J, Botha K, Smit R, Oosthuizen PP: Effects of quetiapine and haloperidol on body mass index and glycaemic control: a long-term, randomized, controlled trial. Int I Neuropsychopharmacol 2005, 8:175-182.

28. Emsley R, Myburgh C, Oosthuizen P, van Rensburg SJ: Randomized, placebo-controlled study of ethyl-eicosapentaenoic acid as supplemental treatment in schizophrenia. Am J Psychiatry 2002, 159:1596-1598.
29. Emsley R, Niehaus DJ, Oosthuizen PP, Koen L, Ascott-Evans B, Chiliza B, van Rensburg SJ, Smit RM: Safety of the omega-3 fatty acid, eicosapentaenoic acid (EPA) in psychiatric patients: results from a randomized, placebocontrolled trial. Psychiatry Res 2008, 161:284-291.

30. Erinfolami A, Ola B, Olagunju A: Impact of atypical and conventional antipsychotics on the quality of life of patients with schizophrenia: a preliminary report from Lagos teaching hospitals. World Psychiatry 2009, 8(suppl1).

31. Fawzi M, Fawzi M Jr: Aripiprazole, olanzapine and olanzapineclomipramine combination in schizophrenia with obsessive-compulsive symptoms. World Psychiatry 2009, 8(suppl1).

32. Golden $\mathrm{G}$, Honigfeld $\mathrm{G}$ : Bioequivalence of clozapine orally disintegrating 100-mg tablets compared with clozapine solid oral 100-mg tablets after multiple doses in patients with schizophrenia. Clin Drug Investig 2008, 28:231-239.

33. Loza N, El-Dosoky AM, Okasha TA, Khalil AH, Hasan NM, Dossenbach M, Kratky P, Okasha A: Olanzapine compared to chlorpromazine in acute schizophrenia. Eur Neuropsychopharmacol 1999, 9:S291.

34. Makanjuola RO, Dixon PA, Oforah E: Effects of antimalarial agents on plasma levels of chlorpromazine and its metabolites in schizophrenic patients. Trop Geogr Med 1988, 40:31-33.

35. Martyns-Yellowe IS: The decanoates of flupenthixol and clopenthixol in the treatment of chronic schizophrenic in-patients. Implications for community psychiatry. West Afr J Med 1993, 12:110-113.

36. Mechri A, Fendri C, Ben Othman L, Mekhinini A, Kerkeni A, Gaha L: Effect of first generation antipsychotic treatment on oxidative stress markers in schizophrenia. Eur Neuropsychopharmacol 2006, 16:S438.

37. Neppe VM: Carbamazepine as adjunctive treatment in nonepileptic chronic in-patients with EEG temporal lobe abnormalities. J Clin Psychiatry 1983, 44:326-331.

38. Odejide OA, Aderounmu AF: Double-blind placebo substitution: withdrawal of fluphenazine decanoate in schizophrenic patients. J Clin Psychiatry 1982, 43:195-196

39. Oosthuizen P, Emsley R, Jadri Turner $\mathrm{H}$, Keyter N: A randomized, controlled comparison of the efficacy and tolerability of low and high doses of haloperidol in the treatment of first-episode psychosis. Int I Neuropsychopharmacol 2004, 7:125-131.

40. Rompel $\mathrm{H}$, Segal $\mathrm{H}$ : A comparison of the relative efficacy of Serenace and chlorpromazine in the treatment of chronic schizophrenics. J Int Med Res 1978, 6:126-132.

41. Sefasi A, Crumlish N, Samalani P, Kinsella A, O'Callaghan E, Chilale H: A little knowledge: caregiver burden in schizophrenia in Malawi. Soc Psychiatry Psychiatr Epidemiol 2008, 43:160-164.

42. Shibre T, Alem A, Abdulahi A, Araya M, Beyero T, Medhin G, Deyassa N Negash A, Nigatu A, Kebede D, Fekadu A: Trimethoprim as adjuvant treatment in schizophrenia: a double-blind, randomized, placebocontrolled clinical trial. Schizophr Bull 2010, 36:846-851.

43. Subramaney U, Brook S, Berk M: A prospective randomised double blind controlled study of the efficacy of lorazepam versus clothiapine in the control of acutely behaviourally disturbed patients. S Afr Med J 1998, 88:307-310.

44. Ukpong DI, Makanjuola RO, Morakinyo O: A controlled trial of modified electroconvulsive therapy in schizophrenia in a Nigerian teaching hospital. West Afr J Med 2002, 21:237-240.

45. Van Wyk AJ, Marais GF: Chlorpromazine, clotiapine and thioridazine-a comparative clinical trial on Bantu psychotic patients. S Afr Med J 1971, 45:945-947.

46. Van Wyk AJ, Grové JJ: Pimozide: an effective, once daily oral therapy for schizophrenia. S Afr Med J 1972, 46:515-517.

47. Vanelle JM, Douki S: A double-blind randomised comparative trial of amisulpride versus olanzapine for 2 months in the treatment of subjects with schizophrenia and comorbid depression. Eur Psychiatry 2006, 21:523-530.

48. Verster GC, Joubert G, Stevens M, van der Merwe H: Generic substitution-comparing the clinical efficacy of a generic substitute for fluphenazine decanoate with the original product. S Afr Med J 1998, 88:260-262.

49. Wessels WH: A comparative study of the efficacy of bilateral and unilateral electroconvulsive therapy with thioridazine in acute schizophrenia. S Afr Med J 1972, 46:890-892.

50. Uys $\mathrm{H}$, Berk $\mathrm{M}$ : A controlled trial of modified electroconvulsive therapy in schizophrenia in a Nigerian teaching hospital. In Proceedings of the 20th 
Collegium Internationale Neuro-Psychopharmacologicum Congress. Melbourne, Australia:; 1996

51. Impact of Family Psychoeducation on Psychosis. http://clinicaltrials.gov/ct2/ show/NCT01172106 (Accessed, February 9, 2012).

52. Study HGDV olanzapine (versus chlorpromazine in Morocco): Unpublished Document Internal to Eli-lilly 2001:1-512. HGDV/Moroco. Data on file. Data supplied to the Cochrane Schizophrenia Group; 2001.

53. Study Investigating the Safety and Tolerability of Multiple Doses of PF-02545920 in Subjects With Schizophrenia. http://clinicaltrials.gov/ct2/ show/NCT00463372 (Accessed, February 9, 2012).

54. Study of preladenant for the treatment of neuroleptic induced akathisia (Study P05145AM1). http://clinicaltrials.gov/ct2/show/NCT00693472 (Accessed, February 9, 2012).

55. Purgato M, Cipriani A, Barbui C: Randomized trials published in Chinese or Western journals: comparative empirical analysis. J Clin Psychopharmacol 2012, 32:354-361.

56. TREC Collaborative Group: Rapid tranquillisation for agitated patients in emergency psychiatric rooms: a randomised trial of midazolam versus haloperidol plus promethazine. BMJ 2003, 327:708-713.

57. Demyttenaere K, Bruffaerts R, Posada-Villa J, Gasquet I, Kovess V, Lepine JP, Angermeyer MC, Bernert S, Morosini P, de GG, et al: Prevalence, severity, and unmet need for treatment of mental disorders in the World Health Organization World Mental Health Surveys. JAMA 2004, 291:2581-2590.

58. Tosh G, Soares-Weiser K, Adams CE: Pragmatic vs explanatory trials: the pragmascope tool to help measure differences in protocols of mental health randomized controlled trials. Dialogues Clin Neurosci 2011, 13:209-215.

59. Alexander J, Tharyan P, Adams C, John T, Mol C, Philip J: Rapid tranquillisation of violent or agitated patients in a psychiatric emergency setting. Pragmatic randomised trial of intramuscular lorazepam v. haloperidol plus promethazine. Br J Psychiatry 2004, 185:63-69.

60. Raveendran NS, Tharyan P, Alexander J, Adams CE: Rapid tranquillisation in psychiatric emergency settings in India: pragmatic randomised controlled trial of intramuscular olanzapine versus intramuscular haloperidol plus promethazine. BMJ 2007, 335:865.

61. Huf G, Coutinho ES, Ferreira MA, Ferreira S, Mello F, Adams CE: TREC-SAVE: a randomised trial comparing mechanical restraints with use of seclusion for aggressive or violent seriously mentally ill people: study protocol for a randomised controlled trial. Trials 2011, 12:180

62. Huf G, Coutinho ES, Adams CE, TREC-SAVE Collaborative group: Physical restraints versus seclusion room for management of people with acute aggression or agitation due to psychotic illness (TREC-SAVE): a randomised trial. Psychol Med 2012, in press.

63. Tol WA, Barbui C, Galappatti A, Silove D, Betancourt TS, Souza R, Golaz A Van OM: Mental health and psychosocial support in humanitarian settings: linking practice and research. Lancet 2011, 378:1581-1591.

64. Patel V, Prince M: Global mental health: a new global health field comes of age. JAMA 2010, 303:1976-1977.

65. Dua T, Barbui C, Clark N, Fleischmann A, Poznyak V, Van OM, Yasamy MT, Yuso-Mateos JL, Birbeck GL, Drummond C, et al: Evidence-based guidelines for mental, neurological, and substance use disorders in low- and middle-income countries: summary of WHO recommendations. PLoS Med 2011, 8:e1001122.

66. Barbui C, Dua T, van Ommeren M, Yasamy M, Fleischmann A, Clark N, Thornicroft G, Hill S, Saxena S: Challenges in Developing Evidence-Based Recommendations Using the GRADE Approach: The Case of Mental, Neurological, and Substance Use Disorders. Plos Medicine 2010, 7:e1000322.

67. De Angelis CD, Drazen JM, Frizelle FA, Haug C, Hoey J, Horton R, Kotzin S, Laine C, Marusic A, Overbeke AJ, et al: Is this clinical trial fully registered?A statement from the International Committee of Medical Journal Editors. N Engl J Med 2005, 352:2436-2438.

68. International Clinical Trials Registry Platform (ICTRP); http://www.who.int/ ictrp/en/.

doi:10.1186/1752-4458-6-9

Cite this article as: Purgato et al: Schizophrenia trials conducted in African countries: a drop of evidence in the ocean

of morbidity? International Journal of Mental Health Systems 2012 6:9.

\section{Submit your next manuscript to BioMed Central and take full advantage of:}

- Convenient online submission

- Thorough peer review

- No space constraints or color figure charges

- Immediate publication on acceptance

- Inclusion in PubMed, CAS, Scopus and Google Scholar

- Research which is freely available for redistribution 